\title{
XPS Investigations on Solid and Vacuum Deposited, Oxidized and Non-oxidized Palladium
}

\author{
Jürgen Kintrup and Harald Züchner \\ Institut für Physikalische Chemie, Westfälische Wilhelms-Universität Münster, Schloßplatz 4/7, \\ D-48149 Münster
}

Z. Naturforsch. 50a, 381 - 387 (1995); received December 16, 1994

Dedicated to Professor W. Müller-Warmuth on the occasion of his 65th birthday

X-ray photoelectron spectroscopy (XPS) has been carried out to study the reaction of differently prepared palladium samples (solid and film Pd) with atmospheric oxygen. A careful curve fitting of the measured $\mathrm{Pd}-3 \mathrm{~d}_{5 / 2}$ peak allows to separate the $\mathrm{Pd}-3 \mathrm{~d}_{5 / 2}$ peak for $\mathrm{Pd}$ in surface PdO from the dominant Pd-3 $\mathrm{d}_{5 / 2}$ peak of the non-oxidized bulk palladium and to determine the chemical shift of the "oxidized" Pd line with high accuracy. Differences in the chemical shifts for the surface PdO on solid and film palladium are explained by a different charging caused by the photoelectric effect in XPS measurements. The smaller charging effect observed for film palladium as compared to solid palladium indicates a stronger oxygen bonding to the (rougher) film palladium. The strong $\mathrm{Pd}-\mathrm{O}$ bonding seems to be an essential reason for the reduced hydrogen-permeability of film palladium compared to solid palladium.

\section{Introduction}

The high hydrogen-permeability and the chemical inertness of palladium have often been utilized when studying hydrogen diffusion in less noble metals like $\mathrm{Vb}$ metals by macroscopic permeation-measuring techniques. These metals are normally covered with oxide layers when being stored at ambient atmosphere, which impede or even prevent the hydrogen uptake and thus the hydrogen permeation. If the oxide layers are removed by annealing or by ion sputtering of the metals under ultra high vacuum (UHV) conditions, and if the cleaned surface is coated with a thin film of palladium by vacuum deposition, reoxidation at the atmosphere or in aqueous solution can be avoided, and the surfaces are "opened" for hydrogen permeation [1].

In a previous investigation [2] it was found that the most favourable vacuum deposited palladium films with highest hydrogen permeabilities could be obtained by applying slow deposition rates and slightly increased substrate temperatures. However, electrochemical hydrogen-permeability measurements on palladium foils and on palladium foils coated with carefully evaporated palladium films [3] showed that the coated palladium foils - regardless by which method they were prepared - did never reach the hydrogen-permeability of the uncoated ones. One rea-

Reprint requests to Prof. Dr. H. Züchner. son for this behaviour seems to be a stronger contamination of the film surface especially with oxygen in comparison to the surface of the solid palladium foil. However, no significant differences in the degree of surface contamination could be detected by SIMSand AES-analysis.

At this point, X-ray photoelectron spectroscopy (XPS), a surface sensitive analytical method which allows - in comparison to AES and SIMS - a better qualitative and quantitative identification of chemical compounds, has been applied to get further information especially about the bonding of oxygen to the differently prepared surfaces (solid and film palladium) and to investigate how far an influence of oxygen on the hydrogen-permeability can be deduced from these measurements.

X-ray diffraction (XRD) and AES measurements are used for further characterization of the samples.

\section{Experimental}

\subsection{Sample Preparation}

Starting material for all samples was a commercially available palladium foil (from Demetron, $99.99 \%, 0.5 \mathrm{~mm}$ thickness). With the exception of sample Pd1 (see Table 1), all samples were cold rolled to a thickness of $0.2 \mathrm{~mm}$, cut to oval slices and cleaned in an ultrasonic bath first with acetone, then with 
Table 1. Preparation conditions of the investigated Pd samples.

\begin{tabular}{lllll}
\hline $\begin{array}{l}\text { Sample } \\
\text { name }\end{array}$ & $\begin{array}{l}\text { Cold rolled } \\
\text { and annealed }\end{array}$ & Polished & $\begin{array}{l}\text { Film } \\
\text { thickness }\end{array}$ & Oxidized \\
\hline Pd1 & $\bigcirc$ & $\times$ & - & $\bigcirc$ \\
Pd2 & $\times$ & $\bigcirc$ & - & $\bigcirc$ \\
Pd3 & $\times$ & $\bigcirc$ & $100 \mathrm{~nm}$ & $\bigcirc$ \\
Pd4 & $\times$ & $\bigcirc$ & - & $\times$ \\
Pd5 & $\times$ & $\bigcirc$ & $100 \mathrm{~nm}$ & $\times$ \\
\hline
\end{tabular}

methanol. The cold rolled samples were annealed for two hours at $1073 \mathrm{~K}$ under high vacuum conditions $\left(p<10^{-5} \mathrm{~Pa}\right)$ to reduce lattice imperfections. Film deposition was carried out in an UHV-apparatus described in $[2,4]$ by evaporating palladium from an electron beam source after heating the samples by an electron beam to remove adsorption layers. The film thickness was determined by a film thickness monitor (Kronos, QM-300). Two samples (Pd4 and Pd5) were oxidized in the Bunsen burner flame until a blue tint (PdO) appeared. Only sample Pd1 has been polished with diamond paste.

\subsection{Measuring Techniques}

The film structure of all non-oxidized samples (Pd1-Pd3) was determined by XRD in a two-circlediffractometer (Seifert \& Co.) with a scintillation counter using $\mathrm{Cu}-\mathrm{K}_{\alpha}$ radiation.

Samples $\mathrm{Pd} 2$ and $\mathrm{Pd} 4$ were investigated with an Auger electron spectrometer (Varian, model no. 9812707).

The XPS apparatus is an ESCA-3 spectrometer (Vacuum Generators) and has been modified with regard to the vacuum system and the data acquisition. The Al-X-ray source emits $\mathrm{K}_{\alpha}$ radiation of $1486.6 \mathrm{eV}$ and reaches a maximum power output of $240 \mathrm{~W}$ $(20 \mathrm{~mA}$ at $12 \mathrm{kV})$. The $150^{\circ}$ concentric-hemisphere analyser is operated in constant analyser transmission (CAT) mode with pass energies of 50 or $20 \mathrm{eV}$. The electron detector is a channeltron. The system is equipped with two turbomolecular pumps and an ion pump. This combination allows us to achieve pressures in the range of $10^{-8} \mathrm{~Pa}$ in the spectrometer and in the range of $10^{-7} \mathrm{~Pa}$ in the preparation chamber. An argon ion gun could be used for sample cleaning. Data acquisition and analysis were controlled with a personal computer (386 DX 40). Spectrometer calibration was done using the characteristic binding en- ergies [5] of $\mathrm{Au}$ and $\mathrm{Cu}$ :

$$
\begin{aligned}
& \mathrm{Au} 4 \mathrm{f}_{7 / 2}=83.98 \mathrm{eV}, \mathrm{Cu} 2 \mathrm{p}_{3 / 2}=932.67 \mathrm{eV}, \\
& \mathrm{Cu} \mathrm{L}{ }_{3} \mathrm{MM}=567.96 \mathrm{eV} \text { and } \mathrm{Cu} 3 \mathrm{p}=75.14 \mathrm{eV} .
\end{aligned}
$$

\section{Results}

\subsection{Sample Structure}

Figure 1 represents the X-ray diffraction pattern of sample Pd2. Only a few, extremely sharp peaks occur, the (200)- and (400)-reflexes being the most intense ones (see Table 2), indicating large crystallites, grown predominantly in a (100)-texture. Like sample Pd2 the XRD pattern of sample $\mathrm{Pd} 3$ contains only reflexes due to a (100)-texture. Because of the approximate penetration depth of the X-rays of a few $\mu \mathrm{m}$, the pattern of sample $\mathrm{Pd} 3$ is dominated by the peaks of the solid palladium substrate. Additional measurements on a sample with a $1000 \mathrm{~nm}$ thick palladium film (prepared under the same conditions as have been applied for sample Pd3) show the same pattern as the solid substrate material, but with slightly enhanced line widths, indicating smaller crystallite sizes of the palladium film or a more disordered structure of the film compared to the substrate. From these experiments it can be concluded that the vacuum deposited films copy the structure of the substrate palladium. However, the crystallite sizes are reduced when a deposition rate of $5 \mathrm{~nm} / \mathrm{s}$ is chosen.

\subsection{AES Results}

The surface composition of sample Pd2 (see Table 3) has been determined by measuring the peak to peak

\begin{tabular}{|c|c|c|c|c|c|}
\hline $\begin{array}{l}2 \Theta / \\
\text { degree }\end{array}$ & $\begin{array}{l}\text { Intensity } \\
(\mathrm{Pd} 2)\end{array}$ & $\begin{array}{l}\text { Peak width } \\
\text { (Pd2)/degree }\end{array}$ & $\begin{array}{l}\text { Intensity } \\
(\mathrm{Pd} 3)\end{array}$ & $\begin{array}{l}\text { Peak width } \\
(\mathrm{Pd} 3) / \text { degree }\end{array}$ & $h k l$ \\
\hline 46.66 & 100 & 0.063 & 100 & 0.068 & 200 \\
\hline 104.79 & 27 & 0.089 & 13 & 0.077 & 400 \\
\hline 119.35 & $\approx 0.4$ & 0.108 & - & - & 331 \\
\hline 124.67 & 7.5 & 0.107 & $\approx 0.5$ & $\begin{array}{l}\text { indeter- } \\
\text { minable }\end{array}$ & 420 \\
\hline
\end{tabular}

Table 2. XRD results for samples $\mathrm{Pd} 2$ and Pd3.

Table 3. Surface composition from AES measurements (sample Pd2).

\begin{tabular}{lllll}
\hline Element & $\mathrm{Pd}$ & $\mathrm{S}$ & $\mathrm{N}$ & $\mathrm{O}$ \\
\hline Content in $\%$ & 84 & 9.0 & $\approx 4.8$ & $\approx 2.2$ \\
\hline
\end{tabular}




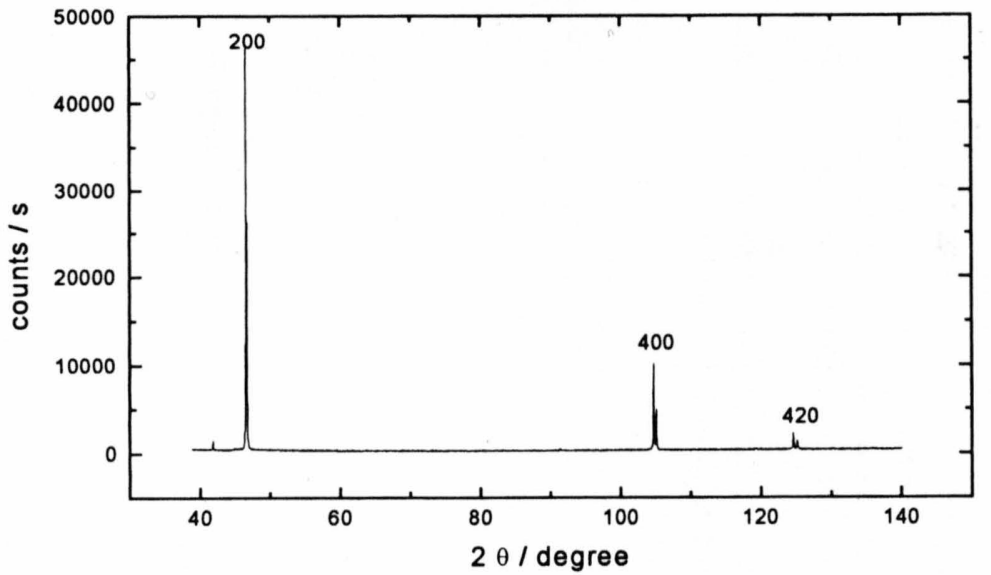

Fig. 1. XRD pattern of sample Pd2.

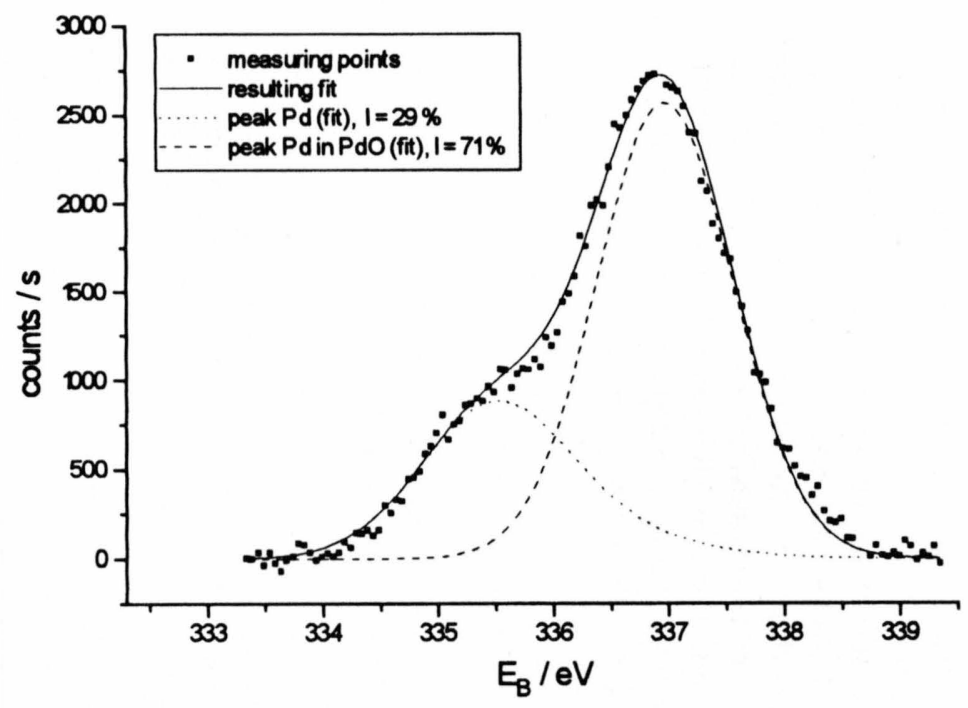

Fig. 4. Curve fitting on Pd- $3 \mathrm{~d}_{5 / 2}$ line, sample Pd4, non-ionsputtered.

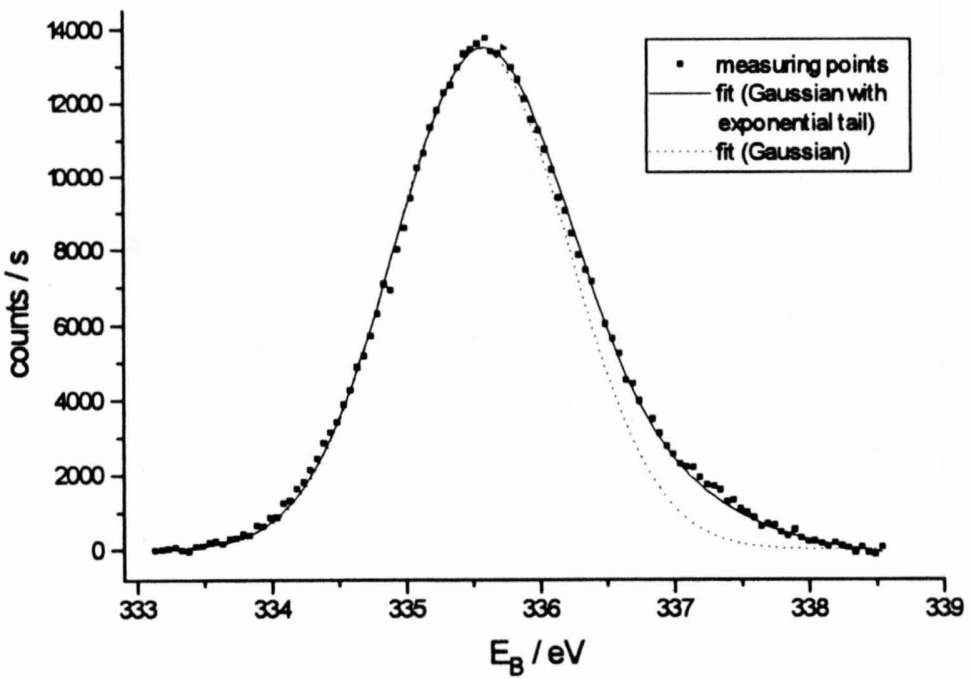

Fig. 3. Curve fitting on Pd-3d ${ }_{5 / 2}$ line, sample Pd2, ion-sputtered.

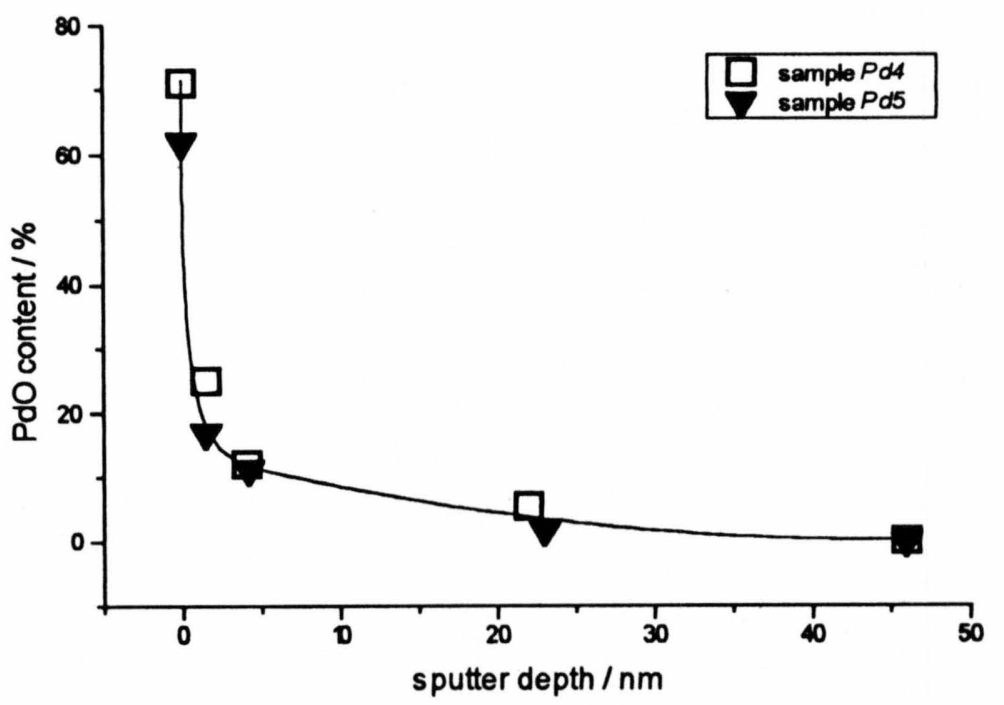

Fig. 5. PdO content (depth profile) of the oxidized samples (Pd4 and Pd5). 


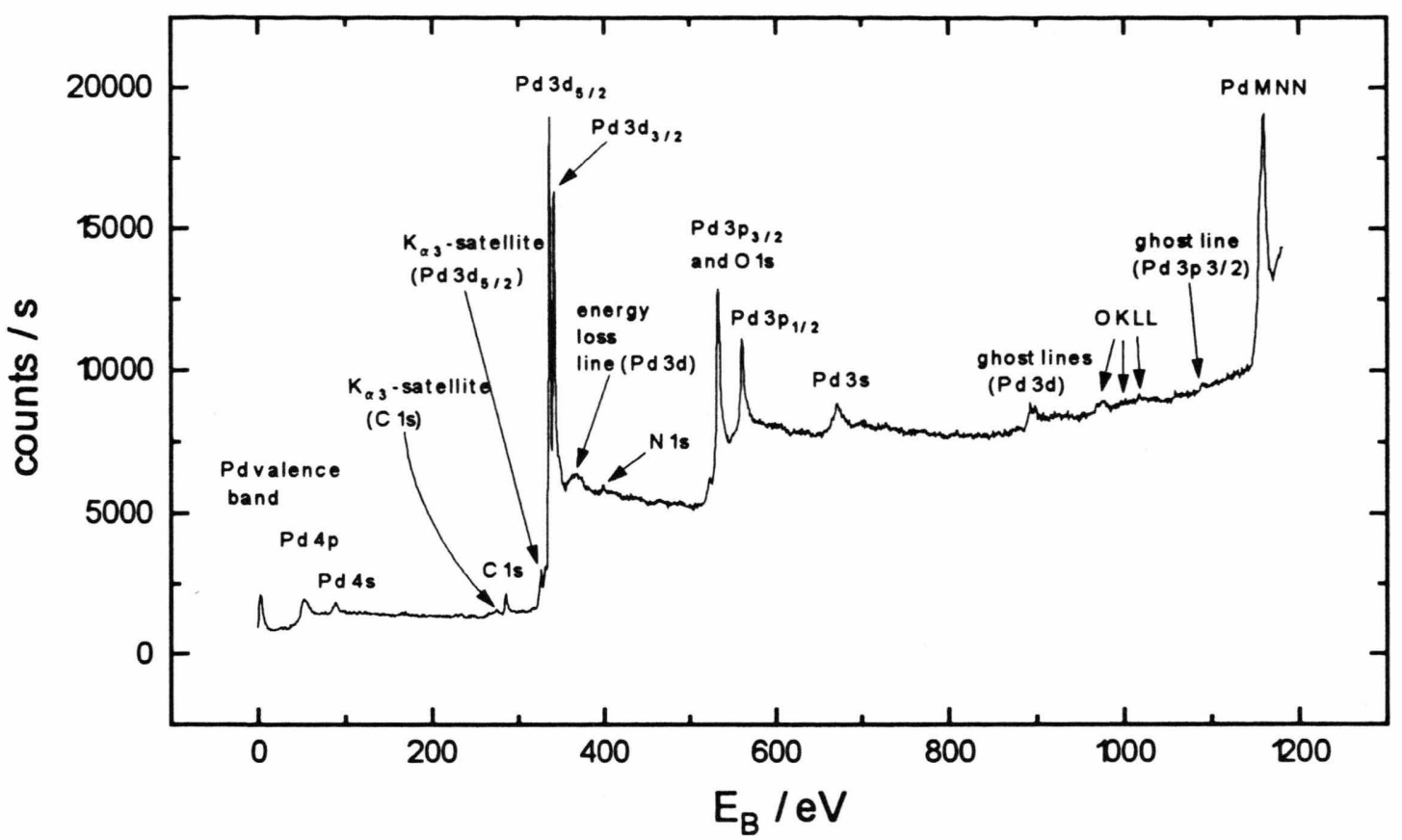

Fig. 2. Wide scan XPS spectrum, sample Pd2, non-ion-sputtered.

amplitude of the Auger spectrum using elemental sensitivity factors [6]. Sulphur, nitrogen and oxygen are the main contaminants.

After several days of baking out the AES apparatus at $473 \mathrm{~K}$, only small $\mathrm{PdO}$ spots - approximately $1 \%$ of the surface area - could be detected on the oxidized sample Pd4. Obviously, the PdO is unstable under these conditions. For this reason baking out the XPS apparatus has been avoided or only done under mild conditions $(T<373 \mathrm{~K}$ and $t<24 \mathrm{~h})$.

\subsection{XPS Results}

The sample compositions (see Table 4) of the nonion-sputtered samples $(\mathrm{Pd} 1-\mathrm{Pd} 3)$ were determined by recording wide scan spectra (see Fig. 2 for an exemplary spectrum) using peak area sensitivity factors [7]. Because of the overlap of the Pd-3 $\mathrm{p}_{3 / 2}$ line with the O-1 s line $\left(E_{\mathrm{B}}=531 \mathrm{eV}\right)$ oxygen can only be detected - but not quantified - by the KLL Auger lines $\left(E_{\mathrm{B}}=978 \mathrm{eV}\right)$.

The high carbon content $\left(E_{\mathrm{B}}(\mathrm{C}-1 \mathrm{~s})=285 \mathrm{eV}\right)$ indicates the presence of hydrocarbons coming of the pump oil, presumably. Comparing the XPS results with the AES ones (see Table 5), which have been obtained in nearly hydrocarbon free vacuum, a fairly good agreement is achieved for the relative contents. As AES is a more surface sensitive method than XPS, the $\mathrm{S}$ content is higher in the AES measurements. The higher $\mathrm{N}$ content in the XPS results is due to slightly worse vacuum conditions of the XPS measurements compared to the AES measurements.

Table 4. Sample composition of samples $\mathrm{Pd} 1-\mathrm{Pd} 3$ in the surface region from XPS measurements, non-ion-sputtered

\begin{tabular}{llll}
\hline Element & Sample Pd1 & Sample Pd2 & Sample Pd3 \\
\hline Pd & $35 \%$ & $45 \%$ & $56 \%$ \\
$\mathrm{C}$ & $58 \%$ & $47 \%$ & $30 \%$ \\
$\mathrm{~S}$ & $\approx 3 \%$ & $3-4 \%$ & $\approx 4 \%$ \\
$\mathrm{O}$ & not quantifiable & not quantifiable & not quantifiable \\
$\mathrm{N}$ & $\approx 4 \%$ & $3-4 \%$ & $10 \%$ \\
\hline
\end{tabular}

Table 5. Comparison of XPS and AES results, sample Pd2, non-ion-sputtered.

\begin{tabular}{llr}
\hline Relative content & XPS & AES \\
\hline$n(\mathrm{~S}) / n(\mathrm{Pd})$ & $7-9 \%$ & $11 \%$ \\
$n(N) / n(\mathrm{Pd})$ & $7-9 \%$ & $6 \%$ \\
\hline
\end{tabular}


After short sputtering with $\mathrm{Ar}$ ions $(30 \mu \mathrm{Amin} \cong$ $2.1 \mathrm{~nm}$ sputter depth) only palladium $(\approx 85 \%)$ and carbon $(\approx 15 \%)$ are detected for the samples Pd1 to Pd3.

By comparison of two detail scan spectra of the Pd- $3 d_{5 / 2}$ line of each of the samples Pd1 to Pd3, one recorded before and one after sputtering, we find a line broadening (by 0.05 to $0.08 \mathrm{eV}$ measured at full width at half maximum) of the non-ion-sputtered samples to the high binding energy side. This points to an overlap of lines with different chemical shifts, and in the present case the only possible palladium compounds with a positive chemical shift can be $\mathrm{PdO}$ and PdS. To clarify the influence of these possible contaminants on the line shape of the Pd- $3 \mathrm{~d}_{5 / 2}$ line, a non-linear least squares curve fitting was performed, first for the $\mathrm{Pd}-3 \mathrm{~d}_{5 / 2}$ line in pure (ion-sputtered) palladium. The used peak function (1) in Table 6 accounts for the natural asymmetry of the line, which is caused by shake-up processes, in using a Gaussian line shape with an exponential tail on the high-binding-energy side [8]. After subtraction of a linear background, five parameters have to be optimized. Two of them (peak centre $\left(x_{0}\right)$ and width $(w)$ at inflection points) were determined manually and held constant at the beginning of the curve fitting.

The $P d-3 d_{5 / 2}$ line shape is fully described by the three parameters:

$$
\begin{aligned}
w & =1.31 \mathrm{eV}, \\
\mathrm{tm} & =0.012519, \\
\mathrm{et} & =3.0442 \mathrm{eV}^{-1} .
\end{aligned}
$$

To emphasize the exponential tail of the peak function, a symmetrical Gaussian line shape is also included in Figure 3.

Table 6. Peak function of Pd- $3 \mathrm{~d}_{5 / 2}$ line (in pure Pd) for nonlinear least squares curve fitting.

$$
\begin{aligned}
& y=f \cdot\left[\operatorname{Gauss}\left(x, y_{0}, x_{0}, w, A\right)\right. \\
& \text { - } \left.\left(1-\operatorname{Gauss}\left(x, y_{0}, x_{0}, w, A\right)\right) T\right] \\
& \text { with: } f=\text { factor } \\
& \operatorname{Gauss}\left(x, y_{0}, x_{0}, w, A\right)=y_{0}+\frac{A}{w \sqrt{\pi / 2}} \exp \left[-2 \frac{\left(x-x_{0}\right)^{2}}{w^{2}}\right] \\
& y_{0}=\text { intercept }\left[\mathrm{s}^{-1}\right] \\
& x_{0}=\text { peak centre }[\mathrm{eV}] \\
& w=\text { width at inflections points }[\mathrm{eV}] \\
& A=\text { peak area }[\mathrm{eV} / \mathrm{s}] \\
& T=\operatorname{tm} \exp \left[\operatorname{et}\left(x-x_{0}\right)\right] \\
& \mathrm{tm}=\text { tail mixing ratio } \\
& \text { et }=\text { exponential tail ratio }\left[\mathrm{eV}^{-1}\right]
\end{aligned}
$$

Measurements on the oxidized samples Pd4 and Pd5 and determination of the line shape and line position of the Pd-3d $\mathrm{d}_{5 / 2}$ line in $\mathrm{PdO}$ were carried out in order to clarify whether differences in the oxidation behaviour of vacuum deposited and solid palladium can be observed.

The line shape of the Pd-3d $\mathrm{d}_{5 / 2}$ line in $\mathrm{PdO}$ (see Fig. 4 for the curve fitting) was assumed to be a (symmetrical) Gaussian one, as no marked shake-up processes occur in electric insulators like PdO, whereas the asymmetrical line shape described above (see Table 6) was taken for the line in the non-oxidized bulk palladium. The resulting characteristic width at the inflection points of the $\mathrm{Pd}-3 \mathrm{~d}_{5 / 2}$ line in $\mathrm{PdO}$ is $w=1.18 \mathrm{eV}$.

The value for the chemical shift of the Pd- $3 \mathrm{~d}_{5 / 2}$ line in PdO depends on the electrostatic charging of the $\mathrm{PdO}$ caused by the photoelectric effect that occurs during the XPS measurements. Generally, the degree of charging depends on the thickness and morphology of the PdO. Island formation or increased thickness of the isolating material promotes higher charging than is found for highly associated PdO cystallites or reduced oxide layer thicknesses. In the present case the charging and chemical shift are reduced from $\Delta E_{\mathrm{B}}=1.58 \mathrm{eV}$ to $\Delta E_{\mathrm{B}}=1.22 \mathrm{eV}$ with increasing sputter depth and decreasing PdO layer thickness. The value of $\Delta E_{\mathrm{B}}=1.22 \mathrm{eV}$ belongs to the chemical shift of $\mathrm{Pd}$ in $\mathrm{PdO}$ if no charging is present, which is in good agreement with the literature $\left(\Delta E_{\mathrm{B}}=1.3 \mathrm{eV}\right.$ [9]).

A depth profile (see Fig. 5) of the oxidized samples $(\mathrm{Pd} 4$ and $\mathrm{Pd5})$ proves that there are no remarkable differences in the oxidation behaviour of the solid and vacuum deposited palladium.

By means of the now well known line shapes of the Pd- $3 \mathrm{~d}_{5 / 2}$ line in pure palladium and in $\mathrm{PdO}$ it becomes apparent that the increased line width of the non-ionsputtered samples $(\mathrm{Pd} 1-\mathrm{Pd} 3)$ is due to a small $\mathrm{PdO}$ content. In the curve fitting procedure (see Fig. 6) the chemical shift between $\mathrm{PdO}$ and pure palladium was not held constant, accounting for possible charging effects (see Table 7 for the results).

Table 7. Chemical shift of Pd- $3 \mathrm{~d}_{5 / 2}$ line and PdO content of the non-ion-sputtered samples.

\begin{tabular}{lll}
\hline Sample & $\Delta E_{\mathrm{B}}(\mathrm{Pd}$ in $\mathrm{PdO}-\mathrm{Pd}) / \mathrm{eV}$ & $\mathrm{PdO}$ content $/ \%$ \\
\hline $\mathrm{Pd} 1$ & 1.72 & 2.8 \\
$\mathrm{Pd} 2$ & 1.53 & 5.4 \\
$\mathrm{Pd} 3$ & 1.40 & 5.0 \\
\hline
\end{tabular}




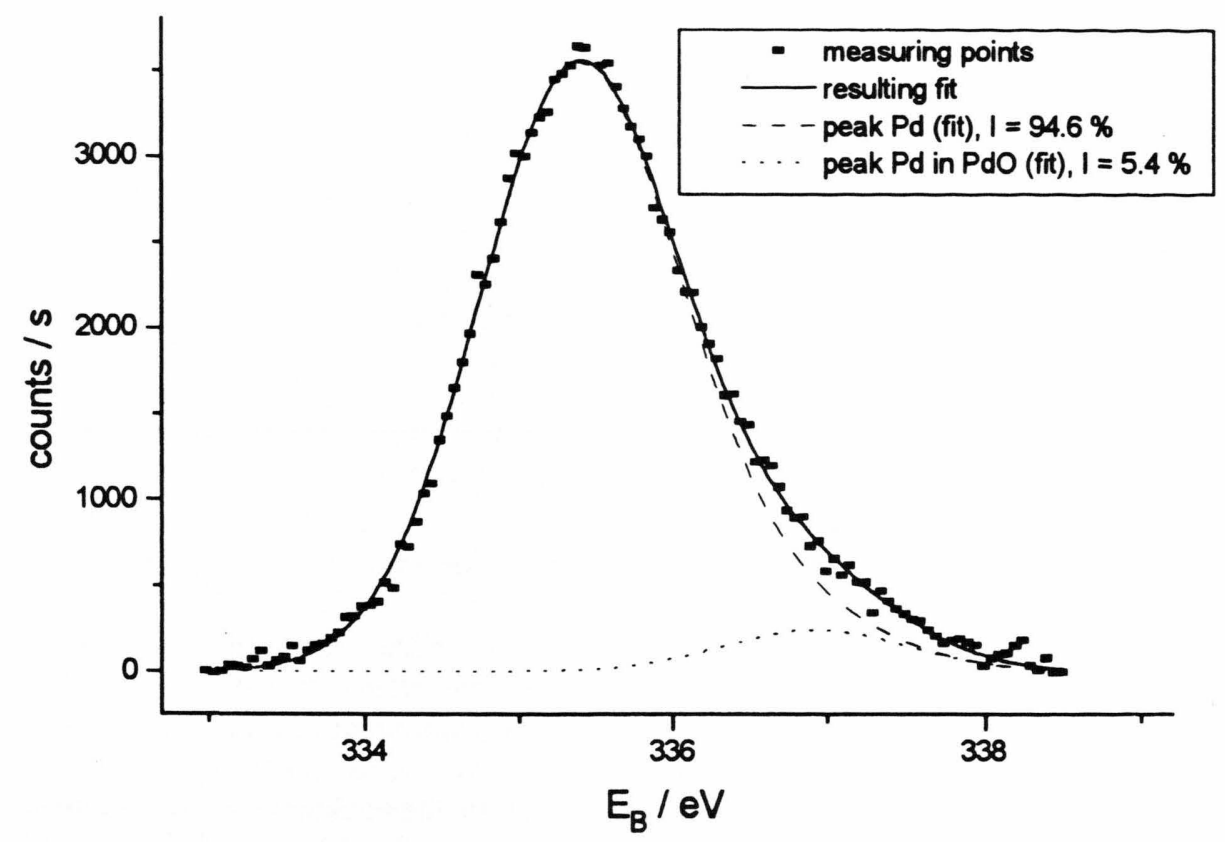

Fig. 6. Curve fitting (example) on Pd-3d $\mathrm{d}_{5 / 2}$ line, sample Pd2, non-ion-sputtered.

The obtained chemical shifts lie in the range of $\Delta E_{\mathrm{B}}(\mathrm{Pd}$ in $\mathrm{PdO})=1.40-1.72 \mathrm{eV}$, which excludes the existence of $\mathrm{PdS}\left(\Delta E_{\mathrm{B}}(\mathrm{Pd}\right.$ in $\mathrm{PdS})=0.8 \mathrm{eV}$ [10]).

In spite of the small $\mathrm{PdO}$ contents, being in the submonolayer range, all samples exhibit a remarkable charging. Obviously, the charging and chemical shift are reduced with increasing surface roughness when going from sample Pd1 to sample Pd3. This statement is confirmed by a similar trend for the $\mathrm{C}-1 \mathrm{~s}$ line.

\section{Discussion and Conclusions}

Solid, polished palladium (sample Pd1) has a smooth surface and is less oxidized at the atmosphere than the unpolished, solid $(\mathrm{Pd} 2)$ or the vacuum deposited (Pd3) palladium. However, in XPS measurements PdO on sample Pd1 exhibits the greatest electrostatic charging, presumably due to a bad electric contact of the surface-PdO to the substrate or an island formation of $\mathrm{PdO}$ crystallites - possibly at imperfections or grain boundaries. The charging is a strong surface effect, as the amount of $\mathrm{PdO}$ on sample Pd1 is extremely small. Thus a bulk effect can be excluded.
With increasing surface roughness of the other samples ( $\mathrm{Pd} 2$ and $\mathrm{Pd} 3)$ the degree of charging decreases. However, some charging remains even on sample $\mathrm{Pd} 3$, as the chemical shift $\left(\Delta E_{\mathrm{B}}=1.40 \mathrm{eV}\right)$ for $\mathrm{Pd}$ in $\mathrm{PdO}$ of the $\mathrm{Pd}-3 \mathrm{~d}_{5 / 2}$ line exceeds the value of $\Delta E_{\mathrm{B}}=1.22 \mathrm{eV}$ obtained for the oxidized but uncharged samples ( $\mathrm{Pd} 4$ and $\mathrm{Pd} 5)$. A rougher, more fine-crystalline and more disordered surface structure facilitates a tighter bonding of the $\mathrm{PdO}$ - but also of other contaminants, e.g. hydrocarbons - to the substrate and thus reduces the charging.

The amount of bulk impurities in the vacuum deposited palladium film is comparable to that in the solid palladium samples. Even under drastic oxidation conditions the thickness of the oxidation layer of the evaporated film (Pd5) does not differ from that of an analogous oxidized solid palladium foil (Pd4).

The attempt to explain the smaller hydrogen-permeability of vacuum deposited palladium films compared to solid palladium by XPS is in principle connected with one fundamental problem: the XPS and AES results have been obtained under UHV conditions which are quite different from the conditions in hydrogen-permeability measurements.

Disregarding this difficulty the following conclusions can be drawn from the above results: 
- A different degree of surface contamination of the solid and vacuum deposited palladium cannot be the main reason for the different hydrogen-permeability of solid and film palladium.

- The different electrostatic charging of the surface $\mathrm{PdO}$ occurring in the XPS measurements indicates differences in the bonding strength of the contaminants on the respective sample surface. A tighter bonding of the contaminants on the evaporated palladium film obviously impedes the hydrogen-

[1] N. Boes and H. Züchner, Phys. Status Solidi (a) 17, K111 (1973).

[2] H. Züchner, H.-J. Schlüter, T. Rauf, and R. Hergemöller, Ber. Bunsenges. Phys. Chem. 95, 1401 (1991).

[3] R. Hergemöller, Thesis, Münster 1988.

[4] N. Boes and H. Züchner, Z. Naturforsch. 31a, 754 (1976).

[5] M. P. Seah, Surf. Interf. Anal. 14, 488 (1989).

[6] P.W. Palmberg, G. E. Riach, R. E. Weber, and N. C. McDonald, Handbook of Auger Electron Spectroscopy, Physical Electronics Industries, Edina, Minnesota 1972 . permeability to a greater extent than do the less weakly bound contaminants on solid palladium.

- The dissociation of hydrogen as the first step of the hydrogen uptake is strongly influenced by surface effects, which are of electric nature. The pure blocking of adsorption sites by contaminants, which often prevents hydrogen uptake from the gas phase, does not seem to be responsible for the lower hydrogen-permeability in vacuum deposited palladium films.

[7] C. D. Wagner, J. Electron Spectrosc. Rel. Phenom. 32, 99 (1983).

[8] P. M. A Sherwood, Data Analysis in X-ray Photoelectron Spectroscopy in: D. Briggs ad M. P. Seah (eds.), Practical Surface Analysis by Auger and X-ray Photoelectron Spectroscopy, John Wiley \& Sons, Chichester 1983.

[9] K.S. Kim, A. F. Gossmann, and N. Winograd, Anal. Chem. 46, 197 (1974).

[10] Y. Matsumoto, M. Soma, T. Onishi, and K. Tamaru, J. Chem. Soc. Faraday Trans. I 76, 1122 (1980). 